\title{
Como a Física aplicada ao trânsito foi abordada no ENEM de 1998 até 2018?
}

\author{
Patrick Alves Vizzotto*, Luiz Fernando Mackedanz ${ }^{* *}$
}

\section{Resumo}

Apresentamos os resultados de uma pesquisa documental que analisou as características de itens do ENEM que abordaram a Física aplicada ao trânsito. Os índices e causas de acidentes reforçam a importância de o tema ser discutido na escola. A Física ganha um papel fundamental no debate, pois pode fornecer subsídios para a compreensão das relações de causa e efeito que os fenômenos científicos podem acarretar em situações do trânsito. Assim, justifica-se o desejo de conhecer como um exame da magnitude do ENEM abordou esse tema, aliado à Física, durante os seus 20 anos de aplicação. Encontramos 33 itens, que foram analisados de acordo com suas características e comparados com os eixos de Alfabetização Científica propostos por Miller (1983). A maioria deles encaixou-se dentro dos parâmetros de itens conteudistas. Nenhum abordou aspectos epistemológicos e apenas uma parcela pequena versou sobre o impacto da ciência e tecnologia na sociedade e ambiente. Além disso, aplicamos a noção de Proficiência Científica para agrupar $24 \%$ dos itens que não puderam ser classificados nos eixos acima mencionados. Ainda sugerimos, em estudos futuros, analisar os 33 itens à luz da psicometria através dos Microdados do ENEM.

Palavras-chave: Alfabetização Científica; Pesquisa Documental; Avaliação.

* Doutor em Educação em Ciências (UFRGS). Bolsista de Pós-doutorado (PNPD/CAPES) da UNIVATES, Brasil. E-mail: patrickvizzotto@gmail.com

* Doutor em Ciências (UFRGS). Professor Associado do Instituto de Matemática, Estatística e Física da FURG. Docente do Programa de Pós-graduação em Educação em Ciências (FURG), Brasil. E-mail: luismackedanz@furg.br

Recebido em: 30/09/2019 - Aceito em: 26/02/2020

https://doi.org/10.5335/rbecm.v3i1.10017

http://creativecommons.org/licenses/by-nc-nd/4.0 


\section{Introdução}

A Física escolar caracteriza-se por abordar conceitos e fenômenos que geralmente fazem parte do cotidiano dos estudantes. Dentre eles, pode-se destacar a cozinha, os esportes, o corpo humano, a medicina, a astronomia, os dispositivos tecnológicos, entre outros. Um desses ambientes é o trânsito. No entanto, embora sejam diversos os contextos que poderiam servir de base para se ensinar Física, nota-se, paradoxalmente, que esse ensino ainda encontra-se permeado por uma abordagem tradicional, centrada no professor e, segundo Moreira (2018), baseado em um modelo de narrativa, bancário e comportamentalista. Para o autor, essa realidade resulta em alunos com baixa predisposição para aprender Física, o que pode atrapalhar o processo de aprendizagem significativa. Com isso, a contextualização de situações cotidianas como base para a socialização dos conhecimentos científicos mostra-se como uma oportunidade relevante para o engajamento dos estudantes.

De inquestionável pertinência pedagógica e social, a associação do trânsito com o estudo da Física pode promover o surgimento de discussões pertinentes para o desenvolvimento de noções críticas das relações de causa e efeito que as leis da Física podem acarretar dentro desse contexto (VIZZOTTO; MACKEDANZ, 2020a). Isso vai ao encontro do "Ensino para a vida" promovido pelos documentos oficiais da educação nacional (BRASIL, 1996, 2018a). Não obstante, segundo Olma (2016), o cotidiano do trânsito sustenta-se sob um tripé que abarca a Educação para o trânsito, o Esforço Legal e as Engenharias de tráfego e veicular. Segundo a autora, quando um acidente ocorre, é em pelo menos um desses pilares que falhas ocorreram. De acordo com Negrini-Neto e Kleinubing (2012), a maior fragilidade é encontrada na Educação para o trânsito. Segundo o relatório anual do Plano Nacional de Redução de Mortes e Lesões no Trânsito (BRASIL, 2018b) a média anual de mortes no trânsito tem sido de aproximadamente 41.900. As três principais causas são, de acordo com a Associação Brasileira de Medicina de Tráfego, em ordem: excesso de velocidade; Consumo de álcool; e Uso do celular. Em todos os casos, podemos perceber que as causas são derivadas das deficiências nos procedimentos de Educação para o trânsito (ABRAMET, 2018).

Nesse diapasão, a Física escolar pode contribuir para esse contexto, elucidando como as leis da natureza podem auxiliar a compreender o cotidiano e os possíveis efeitos derivados de determinadas irresponsabilidades, muito comuns em nossa realidade. Do ponto de vista pedagógico, a associação entre o trânsito e a Física 
pode trazer elementos da realidade dos estudantes, o que pode contribuir para 0 sucesso nas tentativas de contextualização das aulas.

Sob essa realidade, surgiu o desejo de conhecer como um exame da magnitude do Exame Nacional do Ensino Médio (ENEM) abordou esses dois temas em conexão, no decorrer de suas edições. Para responder o questionamento de "Como a física aplicada ao trânsito foi abordada no ENEM durante suas edições?”, realizou-se uma pesquisa documental nas provas de $1^{\underline{a}}$ aplicação realizadas entre 1998 e 2018, analisando os itens e suas características (a coleta de dados ocorreu antes da realização da edição de 2019 do ENEM, o que justifica o recorte das edições até o ano de 2018). Assim, o objetivo do artigo é apresentar os resultados obtidos e discuti-los à luz do referencial teórico da Alfabetização Científica, de acordo com Miller (1983). Os documentos foram acessados no site do INEP e analisados de maneira qualitativa por meio de uma análise de temas principais, fundamentada na análise temática (BRAUN; CLARKE, 2006). Essa análise ressalta os tópicos emergentes destacados a partir da leitura atenta do material examinado. Na próxima seção, apresentamos a fundamentação teórica para as análises realizadas neste manuscrito.

\section{Fundamentação teórica}

O ENEM teve seu início no ano de 1998. Com o passar do tempo, seu formato e metas de aplicação foram se modificando, assim como, as possibilidades educacionais que os participantes do exame poderiam pleitear. Inicialmente, a prova tinha como escopo examinar o concluinte do Ensino Médio, a fim de verificar indícios de competências que pudessem auxiliar o indivíduo na sua atuação cidadã. Também se objetivava a fornecer dados que representassem um indicador da qualidade de ensino (meta que, inicialmente, poderia ser questionada, considerando que o teste não era obrigatório aos estudantes e não havia um delineamento amostral). A prova era composta por 63 questões de múltipla escolha e uma redação. O desempenho de cada participante era aferido por meio do escore de acertos e da nota do texto escrito. As questões seguiam uma matriz de referência que consistia nas diferentes dimensões avaliadas de maneira concomitante, como competências, habilidades e conteúdo. Esse formato de exame vigorou até a prova de 2008.

A partir de 2009 o ENEM assumiu um novo formato. Mudou sua matriz de referência, validação dos itens e análise de desempenho dos participantes, tendo como 
base procedimentos da Teoria de Resposta ao Item (TRI). As metas do exame também passaram por reformulações: Para além de uma inferência da qualidade dos saberes do aluno, seus escores poderiam oferecer também meios para efetuar a classificação dos mesmos no pleito por bolsas de estudo, possibilidade de conclusão do Ensino Médio (até o ano de 2017) e vagas em mais Instituições de Ensino Superior. A nova estrutura teve um aumento na quantidade de questões, sendo composta por 180 itens divididos em 4 áreas: Ciências Humanas, Ciências da Natureza, Linguagens e Códigos e Matemática e suas Tecnologias. Os itens passaram a ser elaborados tendo como referência 5 eixos cognitivos: domínio das linguagens; compreensão dos fenômenos; análise de situações-problema; construção de argumentação; e elaboração de propostas. Em adicional a esses eixos cognitivos, cada área possui também uma matriz de competências e habilidades específicas (BRASIL, 2013). O exame possui ainda como característica a exigência de que seus itens sejam interdisciplinares e contextualizados (RICARDO, 2005). Cada questão do ENEM é retirada do Banco Nacional de Itens, repositório criado pelo Instituto Nacional de Estudos e Pesquisas Educacionais Anísio Teixeira (INEP), a fim de fornecer insumos para diferentes avaliações da esfera federal. Esses itens passam ou deveriam passar, antes da aplicação do exame, por processos de validação de conteúdo, validação estatística e de calibração, onde são aferidos, segundo o seu nível de dificuldade, discriminação e potencial de ser respondido corretamente mediante uma escolha aleatória (modelo logístico de três parâmetros).

No Ensino de Física, diferentes trabalhos já tiveram como foco criticar construtivamente a qualidade dos itens do ENEM. Destacam-se os trabalhos de Bassalo (2011); Gonçalves Júnior e Barroso (2014); Silveira, Stilck e Barbosa (2014); Silva e Martins (2014); Silveira, Barbosa e Silva (2015); Carlos (2016); e Moedinger (2017). É ressaltado na literatura que muitos dos itens de Física, no anseio de contextualizar as situações apresentadas, acabam por distorcer os conceitos neles abordados, resultando em questões com erros conceituais, ambiguidade e interpretação questionável. No entanto, como o foco desse artigo é, inicialmente, entender como o tema trânsito foi abordado na prova durante as suas 20 edições, não nos centraremos na análise da qualidade dos itens, mas sim na exploração da sua caracterização. Essa aferição de qualidade consiste em um tópico de grande mérito para estudos subsequentes.

É esperado que, se cada item seguir a proposta da matriz de referência, tais questões possam atuar na aferição de aspectos da Alfabetização Científica dos respondentes. Julga-se fundamental, então, explanar sobre a concepção de Alfabetização 
Científica empregada neste manuscrito, baseada em Miller (1983). Para o autor, pode ser considerado alfabetizado cientificamente aqueles que apresentarem domínios mínimos no entendimento de 3 eixos: Conteúdos da Ciência (eixo 1); Natureza da Ciência (eixo 2); e Impacto da Ciência e Tecnologia na Sociedade e Ambiente (eixo 3). Essa visão tridimensional aborda aspectos conceituais, como nomenclaturas, significados e contexto histórico; aspectos epistemológicos; e também, pontos que relacionam o tripé Ciência, Tecnologia e Sociedade.

Segundo Miller (1983), não basta dominar apenas os conteúdos e significados da ciência para alguém ser considerado alfabetizado cientificamente, pois as outras duas dimensões são fundamentais para potencializar a crítica da "leitura de mundo" do cidadão. No entanto, há estudos que demonstram que, de maneira majoritária, o eixo conteudista de Miller (1983) é o que os egressos do Ensino Médio mais apresentam aptidão e também é foco de maior abordagem na Educação Básica (CAMARGO et al., 2011; RIVAS, 2017; VIZZOTTO; MACKEDANZ, 2018). Nota-se que a Alfabetização Científica é entendida, pelo autor, como uma característica que ultrapassa o simples entendimento conceitual do conhecimento científico, pois aglutina percepções de aplicação dos saberes no cotidiano e estimula o pensamento crítico para a tomada de decisões. Assim, devido a abrangência conceitual que as suas ideias proporcionam à literatura, adotou-se sua concepção como referencial para analisar as questões de Física aplicada ao trânsito presentes no ENEM. Ou seja, em nossa análise, esperamos que os itens de Física no trânsito possam ser classificados em pelo menos um dos eixos postulados pelo autor. Na sequência, apresentamos os procedimentos metodológicos que guiaram a concretização dos objetivos da pesquisa.

\section{Metodologia}

Esta é uma pesquisa documental, com abordagem qualitativa, inserida dentro da temática da Alfabetização Científica. Os dados foram coletados a partir das provas do ENEM, iniciando no ano de 1998 até a edição de 2018. Por critério de recorte e delimitação, foram analisadas as provas que compuseram a $1^{\mathrm{a}}$ aplicação do ano analisado. Ou seja, não foram objetos de estudo as provas aplicadas a Pessoas Privadas de Liberdade (PPL), Sabatistas, entre outros. Os dados gerados foram debatidos, junto ao referencial teórico, através de uma análise de temas principais fundamen- 
tada na análise temática (BRAUN; CLARKE, 2006). Tal análise tece inferências em tópicos emergentes destacados a partir da apropriação do material pesquisado.

Para Gil (2008), a pesquisa documental assemelha-se com a pesquisa bibliográfica, sendo diferenciada dessa última apenas pela natureza da fonte de informação. A primeira tem como fonte materiais que ainda não receberam um tratamento analítico, enquanto que a segunda faz uso das contribuições de diferentes autores sobre o assunto. Os documentos podem ser classificados como de primeira ou segunda mão. Os de primeira mão ainda não passaram por um processo de análise, como filmes, contratos, cartas, entre outros. Os de segunda mão, por conseguinte, passaram por um tratamento analítico, como por exemplo, relatórios, tabelas estatísticas, etc. Para esta pesquisa, os itens do ENEM podem ser considerados de primeira mão, pois utilizaremos o item desprovido de qualquer tratamento analítico prévio. Trabalhamos com o material bruto e a partir dele produzimos análises.

Assim, a pesquisa aconteceu da seguinte maneira: As provas foram acessadas no site do INEP. Após download para o computador, analisou-se cada uma na procura de itens de Física aplicada ao trânsito. Os critérios para delimitação dos itens de interesse consistiram em a questão envolver diretamente conceitos da Física. $\mathrm{Ou}$ seja, desconsideramos aquelas que apresentavam a temática trânsito, mas estavam associadas a análises limitadas a interpretação matemática de um gráfico ou de uma função, sem uma conexão direta aos conhecimentos da Física escolar. Consideramos, no entanto, questões interdisciplinares dentro da área das Ciências da Natureza que fizessem menção a esta disciplina. Observamos em cada item informações sobre o seu número para localização na prova, a cor da prova analisada, o assunto abordado dentro da Física, se ele exigia cálculos para obter a resposta correta ou apenas o domínio conceitual, e se ele possuía relação com outras áreas. Buscamos também classificar o item de acordo com habilidade e competência na qual ele se propôs inferir. Essas informações serviram de base para fomentar os debates apresentados na seção de discussões. A seguir, apresentamos os resultados da pesquisa.

\section{Resultados}

Ao longo de nossas análises, chegamos a um total de 33 itens que abordaram a Física aplicada ao trânsito no decorrer das 20 edições da prova. Abaixo, o quadro 1 apresenta a frequência de itens para cada ano analisado. 
Quadro 1: Frequência de itens de cada edição do ENEM

\begin{tabular}{|c|c|c|c|}
\hline Ano & $\begin{array}{c}\text { Quantidade } \\
\text { de itens }\end{array}$ & Ano & $\begin{array}{c}\text { Quantidade } \\
\text { de itens }\end{array}$ \\
\hline 1998 & 3 & 2009 & 4 \\
\hline 1999 & 2 & 2010 & 2 \\
\hline 2000 & 0 & 2011 & 1 \\
\hline 2001 & 0 & 2012 & 4 \\
\hline 2002 & 0 & 2013 & 1 \\
\hline 2003 & 3 & 2014 & 0 \\
\hline 2004 & 4 & 2015 & 2 \\
\hline 2005 & 0 & 2016 & 2 \\
\hline 2006 & 0 & 2017 & 2 \\
\hline 2007 & 0 & 2018 & 3 \\
\hline 2008 & 0 & & \\
\hline
\end{tabular}

Fonte: autores.

Nota-se que em 12 das 20 edições do ENEM o tema trânsito foi abordado em itens da Física. Os anos de 2004, 2009 e 2012 apresentaram a maior quantidade de questões sobre a temática, com 4 itens em cada ano. É possível notar que houve maior concentração de itens aplicados ao trânsito após a reformulação do exame, a partir de 2009, pois deste ano em diante, 21 questões abordaram o tema, contra apenas 12 nas edições de 1998 até 2008. Isso pode ser um reflexo da referida exigência de contextualização dos itens. Como o trânsito é um contexto presente no cotidiano da maioria do público-alvo da prova, distingue-se como um ambiente rico para a elaboração de situações envolvendo conhecimentos escolares. Desse universo, 11 itens exigiam a aplicação de fórmulas para sua resolução. Os outros 22 poderiam ser solucionados de maneira conceitual ou com interpretação gráfica. Apenas 6 itens foram identificados com algum traço de relação com outras disciplinas, em uma tentativa interdisciplinar de abordagem, muito embora pudessem ser considerados apenas como pluridisciplinares.

De acordo com Ricardo (2005), os conceitos de contextualização e interdisciplinaridade empregados pelo ENEM são de múltiplas interpretações, até mesmo para os idealizadores do exame. O próprio conceito de interdisciplinaridade propagado nos documentos oficiais auxilia nesta confusão, por não se posicionar quanto à ter- 
minologia que apresenta um caráter polissêmico. Não obstante, segundo o autor, a ideia de interdisciplinaridade não é a de se opor às disciplinas, mas de vislumbrar competências e habilidades que para serem construídas necessitam dos conhecimentos de mais de uma disciplina.

Os itens também foram classificados quanto aos assuntos principais que abordaram: Calorimetria ( 5 itens); Centro de massa ( 1 item); Cinemática ( 5 itens); Dinâmica (3 itens); Dilatação (3 itens); Efeito Doppler (2 itens); Eletrodinâmica (1 item); Energia (9 itens); Hidrodinâmica (1 item); e Movimento Circular (3 itens). Destaca-se o assunto Energia, que foi contexto de 9 questões, no qual a temática trânsito foi abordada dentro de discussões sobre combustíveis. Percebe-se, pelos assuntos dos itens, que a subárea da Física mais utilizada para envolver questões aplicadas ao trânsito foi a Mecânica clássica.

Após o panorama quantitativo apresentado nos parágrafos anteriores, destacamos, na sequência, uma análise de cada item no intento de classificá-los segundo os Eixos da Alfabetização Científica (MILLER, 1983). No quadro a seguir, é possível observar as informações particulares de cada item.

Quadro 2: Relação dos itens com os eixos da Alfabetização Científica e a matriz de referência

\begin{tabular}{|c|c|c|c|c|c|c|c|c|c|c|c|}
\hline \multicolumn{9}{|c|}{ Questões de Física aplicada ao trânsito do ENEM } & \multicolumn{5}{c|}{ Questões de Física aplicada ao trânsito do ENEM } \\
\hline Ano & Cor da prova & Item & Competência & Habilidade & Eixo de Miller & Ano & Cor da prova & Item & Competência & Habilidade & Eixo de Miller \\
\hline 1998 & Amarela & 28 & 3 & 8 & Não classificado & 2010 & Amarela & 47 & 2 & 7 & Eixo 1 \\
\hline 1998 & Amarela & 29 & 3 & 8 & Eixo 1 & 2010 & Amarela & 71 & 6 & 23 & Eixo 1 \\
\hline 1998 & Amarela & 30 & 3 & 8 & Não classificado & 2011 & Amarela & 72 & 6 & 23 & Eixo 3 \\
\hline 1999 & Amarela & 11 & 1 & 1 & Não classificado & 2012 & Branca & 46 & 5 & 18 & Não classificado \\
\hline 1999 & Amarela & 61 & 1 & 3 & Eixo 1 & 2012 & Branca & 72 & 6 & 20 & Eixo 1 \\
\hline 2003 & Amarela & 40 & 2 & 7 & Eixo 3 & 2012 & Branca & 81 & 6 & 21 & Não classificado \\
\hline 2003 & Amarela & 42 & 2 & 7 & Eixo 1 & 2012 & Branca & 86 & 2 & 7 & Eixo 1 \\
\hline 2003 & Amarela & 44 & 3 & 8 & Eixo 3 & 2013 & Amarela & 65 & 5 & 18 & Eixo 1 \\
\hline 2004 & Amarela & 42 & 2 & 7 & Eixo 3 & 2015 & Azul & 49 & 5 & 18 & Eixo 1 \\
\hline 2004 & Amarela & 43 & 3 & 8 & Eixo 3 & 2015 & Azul & 79 & 6 & 21 & Não classificado \\
\hline 2004 & Amarela & 44 & 5 & 17 & Eixo 1 & 2016 & Azul & 49 & 5 & 17 & Eixo 1 \\
\hline 2004 & Amarela & 45 & 5 & 17 & Eixo 1 & 2016 & Azul & 63 & 5 & 17 & Eixo 1 \\
\hline 2009 & Amarela & 18 & 5 & 17 & Eixo 1 & 2017 & Amarela & 93 & 6 & 20 & Eixo 1 \\
\hline 2009 & Amarela & 38 & 5 & 19 & Eixo 1 & 2017 & Amarela & 125 & 6 & 20 & Eixo 1 \\
\hline 2009 & Amarela & 22 & 2 & 7 & Eixo 1 & 2018 & Azul & 92 & 6 & 23 & Eixo 1 \\
\hline 2009 & Amarela & 44 & 5 & 18 & Eixo 1 & 2018 & Azul & 122 & 5 & 17 & Não classificado \\
\hline & & & & & & & & & & & \\
\hline
\end{tabular}

Fonte: autores.

Observamos o ano em que o item foi aplicado, a cor da prova, para ser possível realizar a sua localização mediante o seu número. Ao lado, buscou-se observar se a questão, de modo geral, tinha por objetivo avaliar: aspectos conteudistas, aplicação 
de fórmulas, conceitos, nomenclaturas, interpretações de gráficos (eixo 1); fatores associados a produção do conhecimento e a construção e evolução da ciência (eixo 2); ou por fim, referências que pudessem identificar a reflexão sobre o impacto da ciência em causas sociais e ambientais (eixo 3). Em nossa análise pudemos observar que o eixo 2, subdivisão dedicada a tópicos epistemológicos, não foi contemplada em nenhum item de Física aplicada ao trânsito. Até a edição de 2008, última antes da reformulação do ENEM, notou-se que 41,66\% dos itens puderam ser classificados no eixo 1, mostrando que esses itens tendiam a uma perspectiva conteudista de aferição. Já no eixo 3 foram classificados 33,34\% dos itens, abordando tópicos que relacionavam a Ciência e seus impactos na sociedade e ambiente. Esse aparente equilíbrio foi sensivelmente modificado ao analisarmos as provas a partir de ano de 2009. A partir desse ano, os itens classificados no eixo 1 compuseram 71,40\% do total de itens de Física aplicada ao trânsito. Somente 4,8\% do total desse período pode ser alocado no eixo 3. Com isso, é possível afirmar que, após a sua reformulação, os itens que aliaram a Física e o trânsito no ENEM sofreram uma mudança substancial no foco de aferição, passando a avaliar, majoritariamente, aspectos como retenção conceitual, significados, aplicação de fórmulas e interpretação de gráficos.

Ainda observando o Quadro 2 é possível notar que alguns dos itens foram considerados sem classificação. Isso ocorreu pois o foco dessas questões não se encaixava em nenhum dos três eixos propostos por Miller (1983). Nossa análise verificou que essas questões abordavam a Física aplicada de uma maneira a instigar o respondente a fazer uso dos seus saberes para interpretar a coerência científica e/ou consequência do fato enunciado no contexto do trânsito. Essa perspectiva presume o domínio teórico do fenômeno envolvido, mas não exige que o indivíduo saiba enunciar detalhes do conceito ou qualquer equação para obter êxito em responder o item. Essas questões instigavam o respondente a analisar a coerência científica da situação apresentada e assim, verificar qual alternativa mais se aproximava daquilo que é respaldado do ponto de vista científico. Dos itens de edições anteriores à reformulação do ENEM, 25\% deles apresentaram essa perspectiva. Após a reformulação, o percentual de $23,8 \%$ pode ser classificado nessa visão. As implicações da identificação dessas características será um tópico discutido na próxima seção.

Realizou-se também uma análise das habilidades e competências de cada um dos 33 itens. Mesmo que antes da reformulação realizada em 2009, a matriz de 
referência fosse outra, buscou-se classificar os itens anteriores a esse período para incluí-los também nas discussões. O resultado é apresentado no Quadro 3.

Quadro 3: Questões classificadas de acordo com habilidades e competências

Competência 1: Compreender as ciências naturais e as tecnologias a elas associadas como construções humanas, percebendo seus papéis nos processos de produção e no desenvolvimento econômico e social da humanidade.

Habilidade 1 - Reconhecer características ou propriedades de fenômenos ondulatórios ou oscilatórios, relacionando-os a seus usos em diferentes contextos.

Habilidade 3 - Confrontar interpretações científicas com interpretações baseadas no senso comum, ao longo do tempo ou em diferentes culturas.

Competência 2: Identificar a presença e aplicar as tecnologias associadas às ciências naturais em diferentes contextos.

Habilidade 7 - Selecionar testes de controle, parâmetros ou critérios para a comparação de materiais e produtos, tendo em vista a defesa do consumidor, a saúde do trabalhador (2003-40; 2003-42; ou a qualidade de vida.

Competência 3: Associar intervenções que resultam em degradação ou conservação ambiental a processos produtivos e sociais e a instrumentos ou ações científico-tecnológicos.

Habilidade 8 - Identificar etapas em processos de obtenção, transformação, utilização ou reciclagem de recursos naturais, energéticos ou matérias-primas, considerando processos biológicos, químicos ou físicos neles envolvidos.

Competência 5: Entender métodos e procedimentos próprios das ciências naturais e aplicá-los em diferentes contextos.

Habilidade 17 - Relacionar informações apresentadas em diferentes formas de linguagem e representação usadas nas ciências físicas, químicas ou biológicas, como texto discursivo, gráficos, tabelas, relações matemáticas ou linguagem simbólica.

(2004-44; 2004-45; 2009-18; 2016-49;

Habilidade 18 - Relacionar propriedades físicas, químicas ou biológicas de produtos, sistemas ou procedimentos tecnológicos às finalidades a que se destinam. 2016-63; 2018-122)

(2009-44; 2012-46; 2013-65; 2015-49)

Habilidade 19 - Avaliar métodos, processos ou procedimentos das ciências naturais que contribuam para diagnosticar ou solucionar problemas de ordem social, econômica ou ambiental.

$(2009-38)$

Competência 6: Apropriar-se de conhecimentos da física para, em situações problema, interpretar, avaliar ou planejar intervenções científico-tecnológicas.

Habilidade 20 - Caracterizar causas ou efeitos dos movimentos de partículas, substâncias, objetos ou corpos celestes.

(2012-72; 2017-93;

$2017-125 ; 2018-128)$

Habilidade 21 - Utilizar leis físicas e (ou) químicas para interpretar processos naturais ou tecnológicos inseridos no contexto da termodinâmica e(ou) do eletromagnetismo.

$(2012-81 ; 2015-79)$

Habilidade 23 - Avaliar possibilidades de geração, uso ou transformação de energia em ambientes específicos, considerando implicações éticas, ambientais, sociais e/ou econômicas.

Fonte: autores. 
Com essa classificação, foi possível perceber que, caso essa matriz de referência fosse vigente nos primeiros anos do ENEM, no ano de 1998, os itens de Física aplicada ao trânsito teriam avaliado apenas a habilidade 8 . Também, no ano de 1999, haveria aferido diferentes habilidades de apenas uma competência. Depois, em 2009, os itens que contextualizaram a Física no trânsito avaliaram apenas uma única competência. Nos demais anos as competências e habilidades de cada questão tiveram uma distribuição mais homogênea. Notou-se que na maioria dos itens, habilidades como a 17, voltadas para aquisição e manuseio de informações científicas, estavam conectadas à classificação do Eixo 1 de Miller (1983), eixo dedicado ao entendimento dos conteúdos da ciência. Da mesma maneira, a habilidade 23, por exemplo, responsável por mensurar aspectos relacionados a influências sociais e ambientais dos recursos de energia, esteve relacionada a itens classificados de acordo com Miller (1983) como eixo 3, no qual versa sobre o impacto da ciência e tecnologia na sociedade e ambiente.

\section{Discussões}

As questões do ENEM que envolveram a Física aplicada ao trânsito puderam ser consideradas como ressonantes com as orientações de ensino dos Parâmetros Curriculares Nacionais (PCN) (BRASIL, 2000), pois encaixam dentro de uma matriz de referência composta por competências e suas respectivas habilidades. Todos os itens estavam dentro de um contexto da temática trânsito. No entanto, percebeu-se que apesar de existir uma situação aplicada, muitas das questões referidas como contextualizadas poderiam ser solucionadas sem a presença de tal contexto, pois ao fim de tudo, o item solicitava ao respondente a aplicação de informações em uma equação ou a simples interpretação de um gráfico.

Embora tenha sido possível perceber a existência de questões com o formato voltado aos ideais de uma Física alinhada ao ensino para a vida, constata-se, principalmente após o ano de 2009, que muitos dos itens apresentam um viés conectado a uma visão tradicional, conteudista, muito comum nos exames de vestibular. Isso pode se dar ao fato de que a partir de 2009 o ENEM passou a ser empregado como exame de seleção para diferentes Universidades públicas, para bolsas de estudos, para conclusão do Ensino Médio (até 2017), entre outros, o que faz com que a prova necessite, além de mensurar o nível de entendimento dos participantes, discriminá- 
-los entre os de maior e menor desempenho, a fim de classificá-los ou não em diferentes processos seletivos. Outra hipótese, segundo Hernandes e Martins (2013), é que esse formato de itens aconteça devido a formação conservadora dos elaboradores das questões de Física. Segundo os autores, isso poderia ser amenizado ampliando e aprimorando o banco de questões utilizado para a elaboração do exame.

Quanto à interdisciplinaridade, uma pequena quantidade de itens analisados apresentou ligações com outras áreas. Quando acontecia, os acenos eram apenas com a química ou matemática. Ainda assim, são necessárias discussões de maior profundidade, em produções subsequentes, a fim de avaliar se a abordagem dos itens considerados "interdisciplinares" realmente apresenta características de uma conexão interdisciplinar.

Sobre a análise dos itens em função dos 3 eixos de Miller (1983), já era esperado que nenhum deles avaliasse ao mesmo tempo mais de um eixo. É possível que se o conjunto de itens de Física do Enem fosse capaz de ser analisado sob esta perspectiva, a hipótese de homogeneidade dos 3 eixos pudesse ser testada, sendo esse foco, sugestão para estudos futuros. No que se refere aos itens considerados "Não classificado", a noção de Proficiência Científica (VIZZOTTO; MACKEDANZ, 2020b) pode contribuir para reclassificá-los dentro das ideias postuladas por Miller (1983). Por Proficiência Científica entende-se a aptidão que permite ao indivíduo utilizar os saberes presentes em sua estrutura cognitiva, sejam intrínsecos ou extrínsecos, adquiridos em espaços formais, informais ou não formais de ensino, para interpretar de maneira cientificamente adequada os acontecimentos científicos que possam permear suas vivências cotidianas. Ou seja, aqueles itens que não avaliavam aspectos memorísticos, procedimentos matemáticos ou interpretação de gráficos e sim, instigavam o respondente a fazer uso dos seus saberes para julgar as alternativas dos itens como coerentes ou não, do ponto de vista científico, estavam, dentro dessa perspectiva, aferindo o que se entende aqui como Proficiência Científica.

Esse conceito, em um primeiro momento, pode ser confundido com a noção de Competência, muito citada no contexto do ENEM, nos Parâmetros Curriculares Nacionais (BRASIL, 2000) e, na Base Nacional Comum Curricular (BNCC) (BRASIL, 2018a). Nesse último documento, a noção de competência envolve dimensões além do aprendizado de seus conteúdos conceituais. As Ciências da Natureza e suas Tecnologias, ao articular a Física, Biologia e Química, define competências e habilidades que permitem aprendizagens essenciais sobre: os saberes conceituais da 
área; à contextualização social, cultural, ambiental e histórica desses conhecimentos; os processos e práticas de investigação e às linguagens das Ciências da Natureza (BRASIL, 2018a). Para a BNCC, o tema trânsito encaixa-se como uma situação cotidiana de destaque. No entanto, as temáticas contextualizadas devem superar a simples exemplificação de conceitos com fatos. A Base defende que a aprendizagem deve valorizar a aplicação dos conhecimentos na vida individual, nos projetos de vida, no mundo do trabalho. De acordo com o documento, o êxito nesse desafio pode favorecer o protagonismo dos alunos no enfrentamento de questões aplicadas à suas vidas. Isso pode acontecer por meio do desenvolvimento de determinadas competências e habilidades. Assim, a defesa de um "ensino para a vida" existente no PCN (BRASIL, 2000) é encontrada também dentro da BNCC (BRASIL, 2018a). Em ambos os documentos, a temática do trânsito assume um caráter de relevância para estimular o desenvolvimento de competências que permitam a percepção dos saberes científicos no cotidiano.

Não obstante, a noção de competência proposta pelos documentos oficiais pode assumir significados distintos das referências utilizadas para compreender a ideia de Proficiência Científica. À vista disso, é relevante buscar embasamentos para desambiguar os termos. Para Perrenoud (1999), competência pode ser entendida como uma "capacidade de agir eficazmente em um determinado tipo de situação, apoiada em conhecimentos, mas sem limitar-se a eles" (p. 4). Ao encontro da concepção de Perrenoud (1999), o modelo explicativo de Competência (MORETTO, 2013) proporciona respaldo para ilustrar a função do conceito de Proficiência dentro desse contexto e é definida como composta por uma visão multidimensional. De acordo com este autor, para alguém ser considerado competente em algum setor, necessita apresentar domínio de cinco recursos: conteúdos conceituais, habilidades, domínio de linguagens, valores culturais e administração do emocional. Em determinadas circunstâncias, "um ou dois dos recursos serão mais exigidos que os outros, e, em outras, a falta de um deles pode bloquear todos os outros" (MORETTO, 2013, p. 2). De acordo com essa lógica, deter conhecimentos específicos sobre determinada área é um fator fundamental, embora não exclusivo, para o desenvolvimento de competências de um indivíduo. Nesse sentido, a noção de Proficiência conecta-se a esse referencial a partir do momento que é concebida como uma demonstração da capacidade de fazer uso dos conteúdos conceituais em diferentes aplicações. 
Assim, Proficiência não se confunde com Competência, pois Proficiência é uma demonstração de aptidão de uma das dimensões (conteúdos conceituais) que compõe a ideia de Competência (MORETTO, 2013). Com base na fundamentação exposta, acredita-se que as ideias de Miller (1983), de conceber a Alfabetização Científica sob três eixos aborda em seu eixo 1 apenas aspectos de retenção conceitual dos conteúdos da ciência, mas não possui enfoque na aptidão de aplicá-los em situações da vida. Nesse sentido, sugere-se a incorporação da noção de Proficiência Científica junto ao eixo 1 de Miller (1983), como um eixo complementar ou uma subdivisão do eixo 1 , pois a integração dessa definição pode enriquecer os aspectos teórico-metodológicos da compreensão de significado e da maneira de se inferir o nível de Alfabetização Científica. Assim, transpondo essa noção para a análise dos itens de Física aplicada ao trânsito do ENEM, as questões que não puderam ser classificadas entre os eixos de Miller (1983), podem encontrar agrupamento dentro do eixo complementar ao eixo 1, o eixo da Proficiência Científica, classificando, assim, aproximadamente $24 \%$ dos itens analisados.

\section{Considerações}

O manuscrito apresentou os resultados de uma pesquisa documental que teve como foco analisar as características de itens do ENEM que abordassem a temática da Física aplicada ao trânsito. Investigamos as edições do ENEM desde 1998 até 2018. No total, foram recuperados 33 itens. Apenas 11 deles envolviam a aplicação de fórmulas. Os outros 22 poderiam ser respondidos por meio do raciocínio conceitual ou com interpretação de gráficos. Apenas $18 \%$ dos itens tiveram alguma conexão com outras disciplinas (Química e Matemática). Dentro da Física, a Mecânica clássica foi o tópico mais utilizado como base para a criação dos itens, sendo que o assunto Energia esteve presente em 9 dos 33, estando, de maneira contra-intuitiva, à frente do assunto Cinemática, que embasou 5 questões do total.

Ao classificar os itens com os eixos da Alfabetização Científica de Miller (1983), foi possível concluir que a maioria deles encaixou-se dentro dos parâmetros que os caracterizou como questões de cunho conteudista. Nenhum item abordou o eixo sobre epistemologia e apenas uma parcela pequena de itens teve como foco o impacto da ciência e tecnologia na sociedade e ambiente. Percebeu-se que $24 \%$ das questões não puderam ser classificadas pelos 3 eixos de Miller (1983) pois tinha 
foco de instigar os respondentes a utilizarem seus saberes para efetuar julgamento sobre a coerência científica ou impacto ocorrido nas situações abordadas. Essa característica foi classificada em um eixo complementar aos eixos do referencial, denominada de Proficiência Científica. Ao analisar os itens de Física aplicada ao trânsito do ENEM, entendeu-se como fundamental fazer uso desse conceito para aumentar o entendimento sobre a aferição da Alfabetização Científica a partir das ideias de Miller (1983).

Os eixos de Miller (1983), bem como, a noção de Proficiência Científica, mostraram-se relevantes para auxiliar na classificação dos itens junto das informações de habilidades e competências da matriz de referência. $\mathrm{O}$ tema trânsito está presente no cotidiano da maioria dos indivíduos. Todos são pedestres, passageiros e eventualmente, motoristas. Os índices e as causas dos acidentes de trânsito reforçam a ideia de a importância dessa temática estar presente em discussões dentro da sala de aula.

A Física possui um papel fundamental nesse debate, pois pode fornecer subsídios para a compreensão das relações de causa e efeito que os fenômenos científicos podem acarretar em situações do trânsito. Isso pode, em alguma esfera, contribuir para a conscientização e formação dos cidadãos para uma desejável tomada de decisões crítica e responsável. Não só no Ensino Médio, esse contato com o conhecimento da Física pode produzir, de acordo com Freitas e Andrade Neto (2018), efeitos significativos no engajamento e criticidade dos estudantes desde os primeiros anos do Ensino Fundamental. Assim, a justificativa do estudo aqui apresentado centrou-se no desejo de conhecer como um exame em larga escala nacional abordou esse tema durante os seus 20 anos de aplicação.

Como sugestão para estudos subsequentes, salienta-se a relevância de aprofundar a análise dos itens sob a perspectiva da interdisciplinaridade, a fim de verificar se as questões ditas como interdisciplinares, possuem realmente tais características, ou apenas, são construídas de maneira transversal, ou pluridisciplinar. Incentiva-se também uma análise crítica da coerência teórica de cada uma das questões recuperadas. Outro foco poderia incluir na pesquisa documental versões do ENEM aplicadas a Sabatistas e pessoas privadas de liberdade. Por fim, uma última sugestão é aprofundar a investigação tendo como foco a análise psicométrica do item e a aferição de desempenho dos respondentes dessas questões, por meio dos Microdados disponibilizados pelo INEP. 


\section{How was Traffic Applied Physics Approached in ENEM from 1998 to 2018?}

\section{Abstract}

We present the results of a documentary research that analyzed the characteristics of ENEM items that addressed the physics applied to traffic. The rates and causes of accidents reinforce the importance of the theme being discussed at school. Physics gains a fundamental role in the debate, because it can provide subsidies for the understanding of the relationships of cause and effect that scientific phenomena can lead in traffic situations. Thus, it is justified the desire to know how an examination of the magnitude of the ENEM addressed this theme, allied with Physics, during its 20 years of application. We found 33 items, which were analyzed according to their characteristics and compared with the axes of Scientific Literacy proposed by Miller (1983). Most of them fit within the parameters of theoretical items. None addressed epistemological aspects and only a small portion poured on the impact of science and technology on society and the environment. In addition, we applied the notion of Scientific Proficiency to group $24 \%$ of items that could not be classified in the Miller's axes. We still suggest, in future studies, to analyze the 33 items in the light of psychometry through the ENEM Microdata.

Keywords: Scientific literacy; Documentary research; Assessment.

\section{Referências}

ABRAMET, Associação Brasileira de Medicina do Tráfego. Uso de celular na direção é a terceira causa de mortes no trânsito no Brasil. 2018. Disponível em: <http://stdetranrs.rs.gov. br/conteudo/50876> Acesso em: set. 2019.

BASSALO, José Maria Filardo. Questões de Física do ENEM/2009. Caderno Brasileiro de Ensino de Física, v. 28, n. 2, p. 325-355, 2011.

BRASIL, Lei de diretrizes e bases da educação nacional. Brasília: Ministério da Educação, 1996.

Parâmetros Curriculares Nacionais. Ciências da Natureza. Matemática e suas Tecnologias, Ministério da Educação, Secretaria de Educação Básica, 2000.

, Ministério da Educação. Instituto Nacional de Estudos e Pesquisas Educacionais Anísio Teixeira. Edital no 01, de 08 de maio de 2013. Exame Nacional do Ensino Médio - ENEM 2013. Brasília: MEC/Inep, 2013.

, Base Nacional Comum Curricular - BNCC. Ministério da Educação. Disponível em: http://basenacionalcomum.mec.gov.br/wpcontent/uploads/2018/12 /BNCC_19dez2018_site.pdf., 2018a. Acesso em: set. 2019.

, Relatório anual do plano nacional de redução de Mortes e lesões no trânsito. Ministério das Cidades. 2018b.

BRAUN, Virginia; CLARKE, Victoria. Using thematic analysis in psychology. Qualitative research in psychology, v. 3, n. 2, p. 77-101, 2006. 
CAMARGO, Andrea Norema Bianchi de; PILAR, Fabiana Dias; RIBEIRO, Marcus Eduardo Maciel; FANTINEL, Mirian; RAMOS, Maurivan Guntzel. Alfabetização Científica: A evolução ao Longo da formação de Licenciandos Ingressantes, Concluintes e de Professores de Química. Momento - Diálogos em Educação, v. 20, n. 2, p. 19-29, 2011.

CARLOS, Pablo Rafael de Oliveira. Uma análise do desempenho dos estudantes no exame nacional do ensino médio e as contribuições para o ensino-aprendizagem de física. Juiz de Fora: UFJF. Dissertação de Mestrado: Universidade Federal de Juiz de Fora, 2016.

FREITAS, Savana dos Anjos; ANDRADE NETO, Agostinho Serrano de. A utilização do jogo Angry Birds Space na aprendizagem de conceitos de lançamento de projéteis e de gravidade no ensino fundamental: uma proposta de unidade de ensino potencialmente significativa. Revista Brasileira de Ensino de Ciências e Matemática, v. 1, n. 2, p. 214-225. 2018.

GIL, Antônio Carlos. Métodos e técnicas de pesquisa social. 6. ed. São Paulo: Editora Atlas SA, 2008.

GONÇALVES JR, Wanderley; BARROSO, Marta. As questões de física e o desempenho dos estudantes no ENEM. Revista Brasileira de Ensino de Física, v. 36, n. 1, p. 1402, 2014.

HERNANDES, Jesusney Silva; MARTINS, Maria Inês. Categorização de questões de Física do Novo Enem. Caderno Brasileiro de Ensino de Física, v. 30, n. 1, p. 58-83, 2013.

MILLER, Jon. Scientific literacy: A conceptual and empirical review. Daedalus: Journal of the American Academy of Arts and Sciences, v. 112, n. 12, p. 29-48, 1983.

MOEDINGER, Fernando da Silva. As questões de física do ENEM 2014. Niterói: UFF. Dissertação de Mestrado. Universidade Federal Fluminense, 2017.

MORETTO, Vasco Pedro. Educar para a competência: $O$ desafio do professor no novo contexto educacional. 2013. Disponível em: <https://www.phronesis.net.br/afes/conteudo-detalhes,466, texto,vasco-pedro-moretto-educar-para-competaencias-o-desafio-do-professor-no-novo-contexto-social>. Acesso em: mar. 2020.

MOREIRA, Marco Antônio. Uma análise crítica do ensino de Física. Estudos avançados, v. 32, n. 94, p. 73-80, 2018.

NEGRINI-NETO, Osvaldo; KLEINUBING, Rodrigo. Dinâmica dos acidentes de trânsito: análises, reconstrução e prevenção. Campinas: Millennium, 2012.

OLMA, Maria. Consciência sobre rodas: Habilitação do condutor. 20 ed. Porto Alegre: Águia, 2016.

PERRENOUD, Philippe. Construindo as competências desde a escola. Porto Alegre: Artmed, 1999.

RICARDO, Elio Carlos. Competências, Interdisciplinaridade e Contextualização: dos Parâmetros Curriculares Nacionais a uma compreensão para o ensino das ciências. Florianópolis: UFSC. Tese de Doutorado, Universidade Federal de Santa Catarina, 2005.

RIVAS, Marcela Ines Espinoza; MOÇO, Maria Cecília de Chiara; JUNQUEIRA, Heloisa. Avaliação do nível de alfabetização científica de estudantes de biologia. Revista Acadêmica Licencia\&acturas, v. 5, n. 2, p. 58-65, 2017.

SILVA, Vailton Afonso da; MARTINS, Maria Inês. Análise de questões de Física do Enem pela taxonomia de Bloom revisada. Ensaio Pesquisa em Educação em Ciências, v. 16, n. 3, p. 189-202, 2014. 
SILVEIRA, Fernando Lang da; BARBOSA, Marcia Cristina Bernardes; SILVA, Roberto da. Exame Nacional do Ensino Médio (ENEM): uma análise crítica. Revista Brasileira de Ensino de Física, v. 37, n. 1, p. 1101, 2015.

SILVEIRA, Fernando Lang da; STILCK, Jürgen; BARBOSA, Marcia. Manifesto sobre a qualidade das questões de Física na Prova de Ciências da Natureza no Exame Nacional de Ensino Médio. Caderno Brasileiro de Ensino de Física, v. 31, n. 2, p. 473-479, 2014.

VIZZOTTO, Patrick Alves; MACKEDANZ, Luiz Fernando. Teste de Alfabetização Científica Básica: processo de redução e validação do instrumento na língua portuguesa. Revista Prática Docente, v.3 n. 2, 2018.

VIZZOTTO, Patrick Alves; MACKEDANZ, Luiz Fernando. O uso de testes de hipótese para aferir a existência de diferença no desempenho de egressos do Ensino Médio na tarefa de relacionar a Física com o cotidiano do trânsito. Revista Brasileira de Ensino de Ciências e Matemática, v. 2, n. 2, 2020a.

VIZZOTTO, Patrick Alves; MACKEDANZ, Luiz Fernando. Alfabetização Científica e a Contextualização do conhecimento: um estudo da Física aplicada ao trânsito. Revista Brasileira de Ensino de Física, v. 42, e20190027, 2020b. 